\title{
Modeling and Control of Vinyl Chloride in Drinking Water Distribution Systems
}

\author{
Michael Beardsley ${ }^{1}$ and Craig D. Adams ${ }^{2}$
}

\begin{abstract}
In water distribution systems containing PVC pipe manufactured in the "early era" (prior to 1977), vinyl chloride can leach into drinking water resulting in vinyl chloride concentrations exceeding the $2 \mu \mathrm{g} \cdot \mathrm{L}^{-1}$ maximum contaminant level. Field testing of dead-end segments of water distribution systems consisting of early-era PVC pipe was conducted to examine their initial intrapipe vinyl chloride monomer (VCM) concentrations based on a Fickian-diffusion-based leaching model. The experiments showed a wide range of VCM concentrations within early-era PVC pipe ranging from less than 50 to more than $600 \mathrm{mg} \cdot \mathrm{kg}^{-1}$. Based on the diffusion modeling approach, a protocol was designed that provides a means for utility managers to calibrate the model for specific dead-end lines. The paper delineates procedures to determine which dead ends require flushing to control vinyl chloride, examines the effects of system parameters such as temperature on vinyl chloride leaching, and provides a method to devise flush schedules and volumes. Through a properly designed, tested, and maintained flush protocol such as that developed in this research, public water systems with dead-end lines consisting of early-era PVC pipe can control vinyl chloride concentrations using either manual or automatic flush valves.
\end{abstract}

DOI: 10.1061/(ASCE)0733-9372(2003)129:9(844)

CE Database subject headings: Potable water; Water distribution; Polyvinyl chloride; Models.

\section{Introduction}

Drinking water distribution systems containing "early-era" PVC pipe (manufactured prior to 1977) are at risk of excess vinyl chloride monomer leaching from the pipe into the drinking water between the treatment plant and end user (Mansur 1999). In this study, the writers conducted a series of field experiments in deadend segments of water distribution systems to calibrate a diffusion-based model for vinyl chloride leaching into drinking water. The protocol developed may be used to examine which dead-end lines may require regular flushing, to develop flush schedules for specific dead-end lines, and to adjust the schedules for reasons such as seasonal temperature variations.

Before the problem was recognized in the early 1970s, variable and sometimes excessive amounts of vinyl chloride were employed in the PVC manufacturing process. Estimated vinyl chloride monomer concentrations in early-era PVC pipe range from 20 to 2,000 $\mathrm{mg} \cdot \mathrm{kg}^{-1}$ (Berens 1974; W. Carroll, PVC industry representative, personal communication, April 2000). In 1979, the National Sanitation Foundation (NSF) dictated that the concentration of vinyl chloride in PVC pipe should be no more than $10 \mathrm{mg} \cdot \mathrm{kg}^{-1}$ (NSF 1979). This concentration was later reduced to the current limit of $2 \mathrm{mg} \cdot \mathrm{kg}^{-1}$ [American Water Works Associa-

${ }^{1}$ Graduate Assistant, Dept. of Civil Engineering, 220 Civil Engineering Building, Univ. of Missouri-Rolla, Rolla, MO 65409.

${ }^{2}$ Mathes Professor, Dept. of Civil Engineering, 220 Civil Engineering Building, Univ. of Missouri-Rolla, Rolla, MO 65409 (corresponding author). E-mail: adams@umr.edu

Note. Associate Editor: Teresa B. Culver. Discussion open until February 1,2004 . Separate discussions must be submitted for individual papers. To extend the closing date by one month, a written request must be filed with the ASCE Managing Editor. The manuscript for this paper was submitted for review and possible publication on December 11, 2000; approved on October 21, 2002. This paper is part of the Journal of Environmental Engineering, Vol. 129, No. 9, September 1, 2003. CASCE, ISSN 0733-9372/2003/9-844-851/\$18.00. tion (AWWA) 1988]. Currently, in conjunction with the NSF, the ASTM determines the specifications used for the manufacture of modern PVC pipe (ASTM 2000).

Vinyl chloride is an odorless, colorless volatile organic chemical that can cause liver cancer in humans (Letterman 1999). Hence, the maximum contaminant level goal for vinyl chloride is zero, while its maximum contaminant level (MCL) is set at 2 $\mu \mathrm{g} \cdot \mathrm{L}^{-1}$ (Letterman 1999). Due to its low molecular weight and lack of charge, vinyl chloride is highly volatile with a boiling point of $-13.4^{\circ} \mathrm{C}$ (Merck Index 2001) and a Henry's law constant of $0.0217 \mathrm{~atm} \cdot \mathrm{m}^{3} / \mathrm{gmol}$ (Letterman 1999).

Early-era PVC pipes are still in use today in many water districts throughout the United States. In some of these systems, vinyl chloride concentrations in excess of the MCL are periodically reported, while in others no exceedances have been observed. The majority of the cases of excessive vinyl chloride concentrations in drinking water distribution systems due to leaching from early-era PVC pipe have been reported in Kansas, Missouri, Texas, and Arkansas (Mansur 1999a), although the problem may be more widespread.

Several solutions to the problem of vinyl chloride contamination of drinking water via leaching from PVC pipes are available to water utilities. First, a district may elect to simply replace the early-era pipe with new pipe which meets current ASTM standards. Sites such as Donovan, Kan., have implemented this solution (P. McCool, Kansas Department of Environment and Health, personal communication, September 2000). The costs associated with pipe replacement may vary significantly between locations, depending on pipe depths, nearby roads and structures, proximity to other utility lines, geological conditions, and other factors.

A second potential solution involves utilizing point-of-use treatment devices (at the consumer's tap). This approach, however, is problematic as it requires regular maintenance and relies on the consumer rather than the utility to maintain water safety.

A third, more practical approach is the development and implementation of an appropriate flush protocol. Such a protocol 
would specify criteria to determine when flushing of the lines is needed and what flush volume should be employed. Depending on a utility manager's specific constraints, either manual or automatic flushing through end-of-pipe flush valves could be implemented at relatively low cost.

The research described in this article took this third approach and focused on designing a readily applicable method for utility managers to determine flush criteria, frequency schedules, and flush volumes required to maintain vinyl chloride concentration within selected limits in dead-end lines subject to vinyl chloride concentrations in excess of the MCL. The first objective was to determine the distribution of initial vinyl chloride concentrations present in early-era PVC pipes $\left(C_{0}\right)$ in Missouri water distribution systems. A second objective was the experimental calibration of a diffusion model for vinyl chloride leaching in water distribution systems based on Fickian diffusion principles for specific system parameters (i.e., temperature, water usage rate, pipe diameter and schedule, and pipe age). At these sites, dead-end lines in selected systems were purged and then allowed to rebound with respect to vinyl chloride concentration in the water. The third objective consisted of formulation of a protocol whereby utility managers could achieve two goals: first, utilization of a leaching model to examine drinking water systems in order to determine whether vinyl chloride leaching might lead to unacceptable vinyl chloride concentrations; and second, development of an appropriate flush program to prevent concentrations of vinyl chloride from exceeding the MCL.

\section{Experimental Methods}

\section{Vinyl Chloride Analysis}

Vinyl chloride was analyzed using gas chromatography/mass spectrometry (GC/MS) with purge-and-trap injection via EPA Method 524 (EPA 1999) modified to provide a detection limit of $0.1 \mu \mathrm{g} \cdot \mathrm{L}^{-1}$. This low detection limit was needed to allow an adequate dynamic vinyl chloride concentration range for the field-site model calibration experiments. The GC/MS was performed using a HP 5890 Series II Plus GC and a HP mass selective detector (Hewlett Packard). Two different columns were utilized in this work: a 60-m HP VO column $(25 \mu \mathrm{m}$ diameter $\times 1.5$ $\mu \mathrm{m}$ film thickness) and a 60-m DB-5 column (32 $\mu \mathrm{m}$ diameter $\times 0.25 \mu \mathrm{m}$ film thickness). The chromatographic conditions were as follows: $1.0 \mathrm{~mL} \cdot \mathrm{min}^{-1}$ carrier gas flow rate; $15 \mathrm{psi}$ inlet pressure; $60^{\circ} \mathrm{C}$ injection temperature; $220^{\circ} \mathrm{C}$ detector temperature; and a $60-180^{\circ} \mathrm{C}$ temperature ramp at $15^{\circ} \mathrm{C} \cdot \mathrm{min}^{-1}$.

Injection of the analyte into the $\mathrm{GC}$ was accomplished using a Dynatech Precision Sampling Dynapurge purge-and-trap automatic injector. The method utilized a preheat time of $3 \mathrm{~min}$, an 11-min purge, desorption at $260^{\circ} \mathrm{C}$ for $2 \mathrm{~min}$, and a bake at $270^{\circ} \mathrm{C}$ for $8 \mathrm{~min}$. The sample transfer temperature between the purgeand-trap injector and the $\mathrm{GC}$ was $150^{\circ} \mathrm{C}$.

For quantitative analyses, selected ion monitoring was utilized on the mass spectrometer set to acquire the 62 and 64 mass-tocharge lines. Chemstation software (Hewlett Packard) was used for instrument control and data acquisition. A typical total ion chromatogram and mass spectrum for vinyl chloride are presented in Figs. 1 and 2, respectively.

\section{Vinyl Chloride Sample Collection Protocol}

Samples were collected at flush valves and hydrants at the ends of distribution systems studied as discussed below according to a

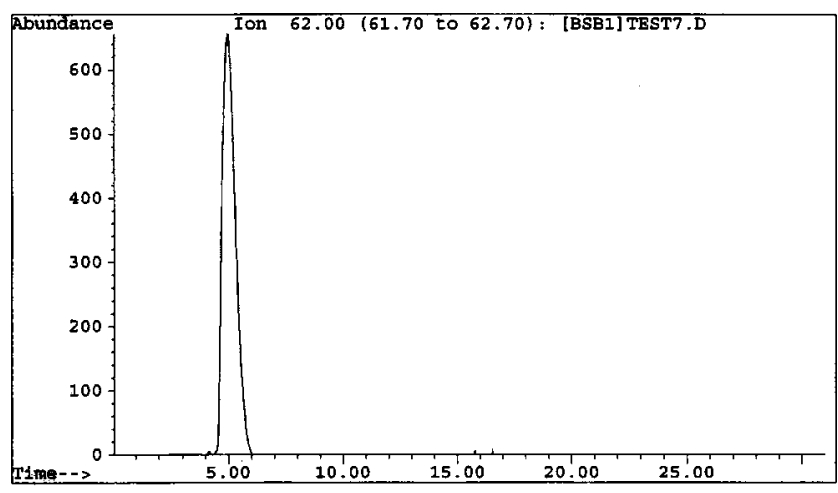

Fig. 1. Total ion chromatograph for vinyl chloride from gas chromatography/mass spectrometry analysis. The same retention time of 5 min was achieved with both columns used by adjusting the carrier gas flow rate between 1 and $2 \mathrm{~mL} / \mathrm{min}$.

sample protocol developed and used by the Missouri Department of Natural Resources (Jerry Lane, personal communication, 1999). As part of this sampling protocol, several gallons of water were first flushed from the flush valve followed by a nearquiescent filling of a 40-mL amber GC vial. Extreme care was taken to prevent agitation of the sample to minimize potential volatilization losses during transfer. To each sample vial, $5 \mathrm{~g} \cdot \mathrm{L}^{-1}$ of sodium thiosulfate were immediately added to remove any residual chlorine. The sample was subsequently acidified with two drops of $50 \%$ hydrochloric acid to inhibit microbial growth. The sample vial was then capped with no headspace with a Teflon-lined septum and plastic lid. The sample temperature, $\mathrm{pH}$, location, and time were recorded at the time of collection. The temperature $\left( \pm 0.1^{\circ} \mathrm{C}\right)$ and $\mathrm{pH}$ were obtained from a separate 2-L sample taken immediately after the vinyl chloride sample using temperature and $\mathrm{pH}$ probes, respectively.

Samples were taken in triplicate at each site, except for the initial site (District A, Site 1, January 2000) where only duplicate samples were collected. Immediately after collection, samples were refrigerated in a cooler. To examine potential vinyl chloride losses from vials prior to analysis, vinyl chloride standards were prepared and handled in the same manner as field samples. They were analyzed according to the GC/MS method previously de-

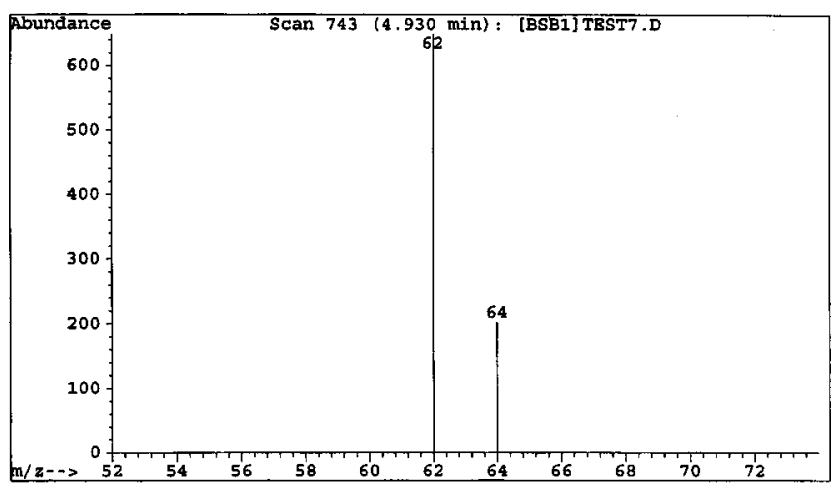

Fig. 2. Mass spectrum for vinyl chloride. Note that ion 64 should have an abundance of about $1 / 3$ that of ion 62 . This is because chlorine exists in two forms; the most common form has an atomic mass of 35 and the other an atomic mass of 37 . The form with a mass of 37 is only $32.4 \%$ as abundant in nature as the form with a mass of 35 (Davis and Frearson 1987). 
scribed. The results showed that standard concentrations were always within $0.2 \mu \mathrm{g} \cdot \mathrm{L}^{-1}$ of the initial concentrations.

\section{Vinyl Chloride Leaching Model Development}

When applied to vinyl chloride monomer diffusion from bulk PVC pipe, Fick's first law of diffusion states that the vinyl chloride mass flux $\left(F, \mathrm{mg} \cdot \mathrm{cm}^{-2} \cdot \mathrm{day}^{-1}\right)$ is proportional to the diffusivity of vinyl chloride within PVC $\left(D, \mathrm{~cm}^{2} \cdot \mathrm{s}^{-1}\right)$ times the concentration gradient (Logan 1999)

$$
F=-D\left(\frac{d C}{d x}\right)
$$

The expression below describes diffusion of a substance into a pipe in which the surface concentration can be assumed to be constant (Crank 1956; Berens and Daniels 1976)

$$
M=4\left(\frac{D t_{a}}{\pi h^{2}}\right)^{1 / 2}+\cdots \approx 4\left(\frac{D t_{a}}{\pi h^{2}}\right)^{1 / 2}
$$

where $M=$ fraction of the original residual vinyl chloride monomer within the PVC that diffused from the pipe in time $\left(t_{a}\right)$; and $h=\mathrm{PVC}$ pipe wall thickness. Upon taking the time derivative, Eq. (2) yields the following:

$$
\frac{d M}{d t}=2\left(\frac{D}{\pi h^{2} t_{a}}\right)^{1 / 2}
$$

where $d M / d t$ is thus the fractional desorption rate for the vinyl chloride from a PVC pipe. Note that $t_{a}$ is an estimate of pipe age since the time of manufacture.

Research by Berens and Daniels (1976) found that the diffusivity for vinyl chloride monomer in PVC can be described as follows:

$$
D=3.7 \cdot \exp \left(\frac{-17,000}{R T}\right)
$$

where $T=$ temperature in kelvin; and $R=$ universal gas constant (1.987 calories $\left.\cdot \mathrm{mol}^{-1} \cdot \mathrm{K}^{-1}\right)$. Berens (1974) originally validated the diffusivity of vinyl chloride in PVC using experiments that measured the diffusion rates of vinyl chloride from PVC powders.

To develop a mass balance on vinyl chloride around the water within a section of pipe of length $L$, the desorption of vinyl chloride on a per weight basis from the PVC pipe $\left(\Delta C_{p}, \mathrm{mg} \cdot \mathrm{kg}^{-1}\right)$ can be expressed in this manner (Berens and Daniels 1976)

$$
\Delta C_{p}=C_{0}\left(\frac{d M}{d t}\right)_{a} t_{R}
$$

where $t_{R}=$ hydraulic retention time of a plug of water within a section of pipe; $d M / d t_{a}=$ fractional diffusion rate of vinyl chloride; and $C_{0}=$ initial concentration of vinyl chloride monomer within the PVC pipe $\left(\mathrm{mg} \cdot \mathrm{kg}^{-1}\right)$ at the time of manufacture. Next, the change in vinyl chloride concentration in the pipe itself and in the water within the pipe is related to the volumes of pipe and water ( $V_{p}$ and $V_{w}$, respectively)

$$
\frac{\Delta C_{w}}{\Delta C_{p}}=1.4 \frac{V_{p}}{V_{w}}
$$

where $1.4=$ specific gravity of vinyl chloride. From geometric considerations, the pipe-to-water volume ratio is described by Eq. (7)

$$
\frac{V_{p}}{V_{w}}=\frac{\left\{[d+2 \cdot(h / 2)]^{2}-d^{2}\right\}}{d^{2}}
$$

where $d=$ internal diameter of the pipe; and $h=$ pipe wall thickness. Note that only a pipe thickness of $h / 2$ is considered; that is, the model assumes that the vinyl chloride in the inner half of the pipe wall diffuses inward into the intrapipe water and the vinyl chloride in the outer half of the pipe wall diffuses outside the pipe. The hydraulic residence time $\left(t_{R}\right)$ within a section of pipe of length $L$ may be expressed as

$$
t_{R}=\frac{\left[(\pi / 4) d^{2} L\right]}{Q}
$$

where $Q=$ hydraulic flow rate within the pipe. In stagnant conditions, the residence time is simply the time that a slug of water sits within a section of pipe. According to mass balance considerations, the net increase in vinyl chloride within a section of pipe per unit volume is as follows:

$$
\Delta C_{w}=C_{0}\left(1.4 \frac{V_{p}}{V_{w}}\right)\left(\frac{d M}{d t}\right)_{a} t_{R}
$$

in units of $\mathrm{mg} \cdot \mathrm{kg}^{-1}$ of water (or parts per million by weight, or $\left.\mathrm{mg} \cdot \mathrm{L}^{-1}\right)$. Upon substitution this yields

$$
\begin{aligned}
\Delta C_{w}= & \left(\frac{\Delta C_{w}}{\Delta C_{p}}\right) \cdot\left(\Delta C_{p}\right)=\left(\frac{\Delta C_{w}}{\Delta C_{p}}\right) \cdot\left(C_{0} \cdot \frac{d M}{d t} \cdot t_{R}\right) \\
= & \left(1.4 \frac{\left\{[d+2 \cdot(h / 2)]^{2}-d^{2}\right\}}{d^{2}}\right)\left[C_{0} 2\left(\frac{D}{\pi h^{2} t_{a}}\right)^{1 / 2}\right] \\
& \times\left\{\frac{\left[(\pi / 4) d^{2} L\right]}{Q}\right\}
\end{aligned}
$$

Note also that the final concentration $\left(C_{\text {final }}\right)$ achieved in bulk solution is equal to the assumed initial concentration $\left(C_{\text {initial }}\right)$ plus the increase in concentration

$$
C_{\text {final }}=C_{\text {initial }}+\Delta C_{w}
$$

Berens and Daniels (1976) validated this modeling approach using data of O'Mara and DeCapita (1975) over leaching times of 3-14 days. Their results showed a strong correlation between experimental and calculated vinyl chloride concentrations ( $r$ $=0.986, p<0.0001)$.

Examination of Eq. $(10 b)$ shows that initial vinyl chloride concentration in the pipe $\left(C_{0}\right)$, pipe diameter $(d)$, wall thickness $(h)$, vinyl chloride diffusivity within PVC $(D)$, pipe section length $(L)$, and flow rate $(Q)$ all affect the increase in vinyl chloride concentration in the bulk water within the pipe. Temperature directly impacts the resulting increase in vinyl chloride by increasing the vinyl chloride diffusivity.

Eqs. (10) and (11) may be used to determine the increase and final vinyl chloride concentration within a section of pipe based on a set of system parameters and an assumed initial vinyl chloride concentration in the pipe $\left(C_{0}\right)$. Additionally, since all of the parameters in Eq. (10) except $C_{0}$ can be measured or determined, $C_{0}$ for a given experiment in a specific dead-end line can be estimated for that pipe section. This is the method that was utilized to estimate $C_{0}$ values for pipes examined in the rebound studies in this research.

Finally, Eqs. (10a) and (11) may be used to determine the time $\left(t_{R}\right)$ required to reach some predetermined vinyl chloride concentration in solution. This was the method used in this research to determine the maximum allowable leaching time (MALT) that 
Table 1. Summary of Number of Sites and Pipe Type within Each District in Study

\begin{tabular}{|c|c|c|}
\hline District & Number of sites & Type of pipe \\
\hline A & 4 & 2-in. SDR 21 and Schedule 40 \\
\hline $\mathrm{B}$ & 1 & 2-in. Schedule 40 \\
\hline $\mathrm{C}$ & 4 & 2-in. likely SDR 21 \\
\hline $\mathrm{D}$ & 1 & 2-in. Schedule 40 \\
\hline $\mathrm{E}$ & 4 & $\begin{array}{l}\text { 1.5- and 2-in. (two sites), } \\
\text { 1.5- and 2-in. (one site), and 2-in. (one site) } \\
\text { Schedule } 40 \text { or SDR } 21\end{array}$ \\
\hline $\mathrm{F}$ & 2 & $\begin{array}{c}\text { 3-in. (one site) and 4-in. (one site) } \\
\text { Schedule } 40\end{array}$ \\
\hline G & 3 & $\begin{array}{c}\text { 2-in. (one site), } 2.5 \text {-in. (one site), and } \\
\text { 2- and 2.5-in. (one site) likely } \\
\text { Schedule } 40\end{array}$ \\
\hline $\mathrm{H}$ & 4 & $\begin{array}{l}\text { 2-in. (three sites) and 2- and 3-in. (one site) } \\
\text { Schedule } 40\end{array}$ \\
\hline Total & 23 sites & \\
\hline
\end{tabular}

corresponded to a maximum allowable concentration (MAC) of 1 $\mu \mathrm{g} \cdot \mathrm{L}^{-1}$ assuming an initial concentration in the bulk solution of $0.5 \mu \mathrm{g} \cdot \mathrm{L}^{-1}$. The reason for assuming a MAC of $1 \mu \mathrm{g} \cdot \mathrm{L}^{-1}$ rather than the MCL of $2 \mu \mathrm{g} \cdot \mathrm{L}^{-1}$ was to provide a more conservative result (discussed in more detail below). An initial vinyl chloride concentration of $0.5 \mu \mathrm{g} \cdot \mathrm{L}^{-1}$ was assumed for modeling purposes due to a lack of information on concentrations below this level available to the authors. Specifically, $0.5 \mu \mathrm{g} \cdot \mathrm{L}^{-1}$ is the method detection limit for vinyl chloride in the laboratories used by the Missouri Department of Natural Resources, and hence for most of the data available to the authors. These conservative assumptions build in a safety factor for the leaching model protocol.

\section{Rebound Study Protocol}

The first objective of this study was to determine the range of $C_{0}$ values observed in water distribution systems containing early-era PVC pipes. Essentially, pipes were flushed and then allowed to rebound with respect to vinyl chloride concentration. Eq. (10) was then applied to determine $C_{0}$ for each system examined.

To select study locations, water distribution systems in Missouri comprised of early-era PVC pipe were identified. The selected sites provided a wide range of system characteristics regarding pipe diameter, wall thickness, pipe age, and water temperature. Because non-dead-end lines have not generally resulted in significant vinyl chloride concentrations, only dead-end systems (the worst case in terms of residence times) were examined. Overall, 23 sites in eight different water districts (denoted Districts A-H) were examined (Table 1). In all systems, the pipe diameter(s) was (were) known, although the pipe schedule (i.e., pipe size) was not always known with certainty. However, studies have shown the difference in leaching from the two most common schedule PVC pipe types (i.e., "SDR 21" and "Schedule 40") is negligible (A. Berens, unpublished internal Uni Bell PVC document, 2000).

The rebound study protocol involved flushing two to three gallons of water from a flush valve or hydrant at the end of a dead-end line followed by the collection of an initial set of samples for vinyl chloride analysis. Next, a volume of water in excess of the entire dead-end volume was flushed from the line to provide very low vinyl chloride concentrations at the beginning of the rebound period. Another set of samples was then collected; these were denoted as initial samples for the rebound study. Subsequent sample sets were taken every $24-48 \mathrm{~h}$ for the first 5 days, and then every 5 days for up to 18 days. Each rebound study resulted in five or six sample times with each sample being collected in triplicate (or duplicate for one sampling event).

After a set of rebound studies and analyses were complete, the results were used to estimate initial bulk vinyl chloride concentrations $\left(C_{0}\right)$ within the PVC pipes based on the previously developed model. Least-squares regression was used to determine the fit of the rebound results and no data were excluded.

\section{Results and Discussion}

\section{Initial Bulk Vinyl Chloride Concentrations}

Although all of the PVC pipes in the dead-end lines examined in this study were installed between 1960 and 1977, many of the systems consistently exhibited vinyl chloride concentrations below the method detection limit of $0.1 \mu \mathrm{g} \cdot \mathrm{L}^{-1}$ (Table 2). This was an expected result based on the knowledge that wide variability in the amount of vinyl chloride used in PVC manufacture resulted in certain lots of pipe with exceedingly low vinyl chloride concentrations.

For the dead-end lines examined, the range of initial concentration for samples taken prior to the initial flush ranged from nondetectable to $9.4 \mu \mathrm{g} \cdot \mathrm{L}^{-1}$. Vinyl chloride concentrations were even measured at levels of approximately $25 \mu \mathrm{g} \cdot \mathrm{L}^{-1}$ in one deadend line on two separate occasions, though not immediately preceding a rebound study. Rebound studies were generally conducted over approximately a one- to three-week period. At the end of this period, the range of vinyl chloride concentrations observed extended from nondetectable $\left(<0.1 \mu \mathrm{g} \cdot \mathrm{L}^{-1}\right)$ to 11.6 $\mu \mathrm{g} \cdot \mathrm{L}^{-1}$.

To examine the leaching model [Eq. (10)], predicted vinyl chloride concentrations were plotted against the concentrations measured in the field using $C_{0}$ values calibrated from rebound study data (Fig. 3). Because regressed values of $C_{0}$ were used in the predictions, a strong correlation $(r=0.95)$ was observed. Examination of the low concentration portion of Fig. 3 reveals that in no case did the observed concentration for vinyl chloride exceed the $2 \mu \mathrm{g} \cdot \mathrm{L}^{-1} \mathrm{MCL}$ if the predicted value was $1 \mu \mathrm{g} \cdot \mathrm{L}^{-1}$ or less. This suggests that an appropriate maximum allowable concentration of vinyl chloride for application of the model to develop a flush protocol might be $1 \mu \mathrm{g} \cdot \mathrm{L}^{-1}$.

\section{Determination of Required Flush Frequencies and Flush Volumes}

To facilitate the application of the previously developed leaching model to actual systems, a series of plots were developed for various initial vinyl chloride concentrations $\left(C_{0}\right)$, temperatures, and pipe diameters (Fig. 4). From these plots, the MALT to reach a MAC of $1 \mu \mathrm{g} \cdot \mathrm{L}^{-1}$ of vinyl chloride can be determined. To demonstrate the protocol devised for the determination of required flush frequencies and volumes, the following example is presented.

\section{Model Application Example}

As an illustration of flush protocol development, consider a 0.75 mi. dead-end line in a rural water district containing early-era, 2.0-in., Schedule 40 PVC pipe installed in the 1960s. The water 
Table 2. Summary of Initial Vinyl Chloride Concentrations with PVC Pipes $\left(C_{0}\right)$ Determined in Rebound Studies

\begin{tabular}{|c|c|c|c|c|c|c|c|c|}
\hline District & Hydrant & Temperature $\left({ }^{\circ} \mathrm{C}\right)$ & $\mathrm{pH}$ & Preflush $(\mu \mathrm{g} / \mathrm{L})$ & Postflush ( $\mu \mathrm{g} / \mathrm{L})$ & Final $(\mu \mathrm{g} / \mathrm{L})$ & Days & $C_{0}(\mathrm{mg} / \mathrm{kg})$ \\
\hline \multirow[t]{5}{*}{$\mathrm{A}$} & 1 & 7.0 & 7.3 & 2.4 & 0.1 & 1.2 & 7 & 225 \\
\hline & 1 & 11.9 & 7.2 & 3.4 & ND & 7.3 & 21 & 336 \\
\hline & 2 & 11.9 & 7.3 & 1.3 & ND & 6.1 & 21 & 277 \\
\hline & 3 & 11.1 & 7.3 & ND & ND & 0.8 & 21 & 34 \\
\hline & 4 & 8.1 & 7.3 & ND & ND & ND & 8 & NA \\
\hline $\mathrm{B}$ & 1 & 4.9 & 7.5 & ND & ND & ND & 8 & NA \\
\hline \multirow[t]{4}{*}{$\mathrm{C}$} & 1 & 7.0 & 7.2 & ND & ND & ND & 7 & NA \\
\hline & 2 & 6.1 & 7.4 & ND & ND & ND & 7 & NA \\
\hline & 3 & 6.6 & 7.2 & ND & ND & ND & 7 & NA \\
\hline & 4 & 6.5 & 7.2 & ND & ND & ND & 7 & NA \\
\hline $\mathrm{D}$ & 1 & 7.9 & 7.5 & ND & ND & ND & 7 & NA \\
\hline \multirow[t]{4}{*}{$\mathrm{E}$} & 1 & 9.3 & 7.9 & 0.1 & 0.3 & 1.8 & 11 & 220 \\
\hline & 2 & 9.3 & 8.0 & 0.4 & 0.5 & 0.9 & 11 & 100 \\
\hline & 3 & 9.1 & 8.1 & 0.5 & 0.4 & 1.6 & 11 & 200 \\
\hline & 4 & 10.2 & 8.1 & 1.7 & 0.7 & 3.8 & 11 & 400 \\
\hline \multirow[t]{2}{*}{ F } & 1 & 9.0 & 7.6 & ND & 0.4 & 0.4 & 11 & NA \\
\hline & 2 & 9.4 & 7.4 & 0.4 & 0.4 & ND & 11 & NA \\
\hline \multirow[t]{3}{*}{$\mathrm{G}$} & 1 & 19.3 & 7.3 & 9.4 & 0.2 & 8.4 & 16 & 410 \\
\hline & 2 & 21.1 & 7.3 & 0.5 & 0.2 & 0.8 & 16 & 62 \\
\hline & 3 & 20.0 & 7.3 & 4.9 & 0.3 & 11.6 & 16 & 610 \\
\hline \multirow[t]{4}{*}{$\mathrm{H}$} & 1 & 18.6 & 8.3 & 0.3 & ND & 1.1 & 16 & 47 \\
\hline & 2 & 18.6 & 8.5 & 0.6 & 0.1 & 2.3 & 16 & 130 \\
\hline & 3 & 18.9 & 8.5 & 0.2 & 0.1 & 0.4 & 16 & 38 \\
\hline & 4 & 19.0 & 8.4 & 0.1 & ND & 1.1 & 16 & 67 \\
\hline
\end{tabular}

Note: $\mathrm{ND}=$ not detected; $\mathrm{NA}=$ not applicable.

temperature is $50^{\circ} \mathrm{F}$ and it is assumed that modeling may be based on a MAC of $1 \mathrm{ppb}$ of vinyl chloride. There is a single connection on the dead end near the end of the line. The utility recognizes that, if the occupants leave for some extended period, flushing of the line may be necessary to purge accumulated vinyl chloride. The utility wants to determine, however, when the line needs to be flushed on a regular basis and what flush volume to use.

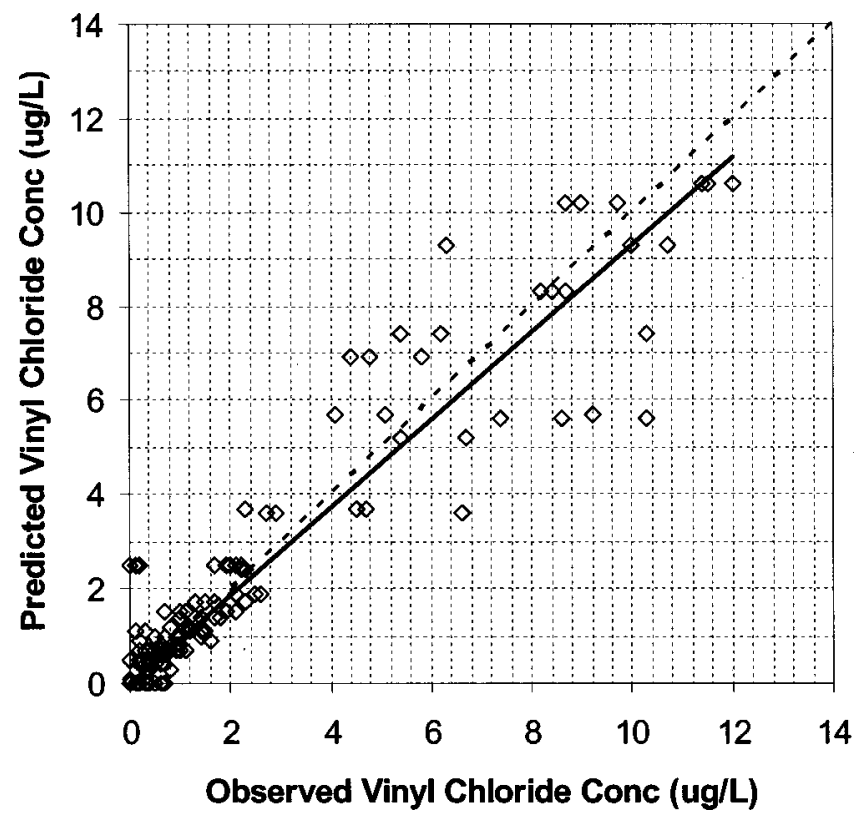

Fig. 3. Predicted versus observed concentration of vinyl chloride in the water using the Fickian-based leaching model. Solid line indicates least-squares fit $(r=0.95)$. Dashed line is line of perfect correlation.

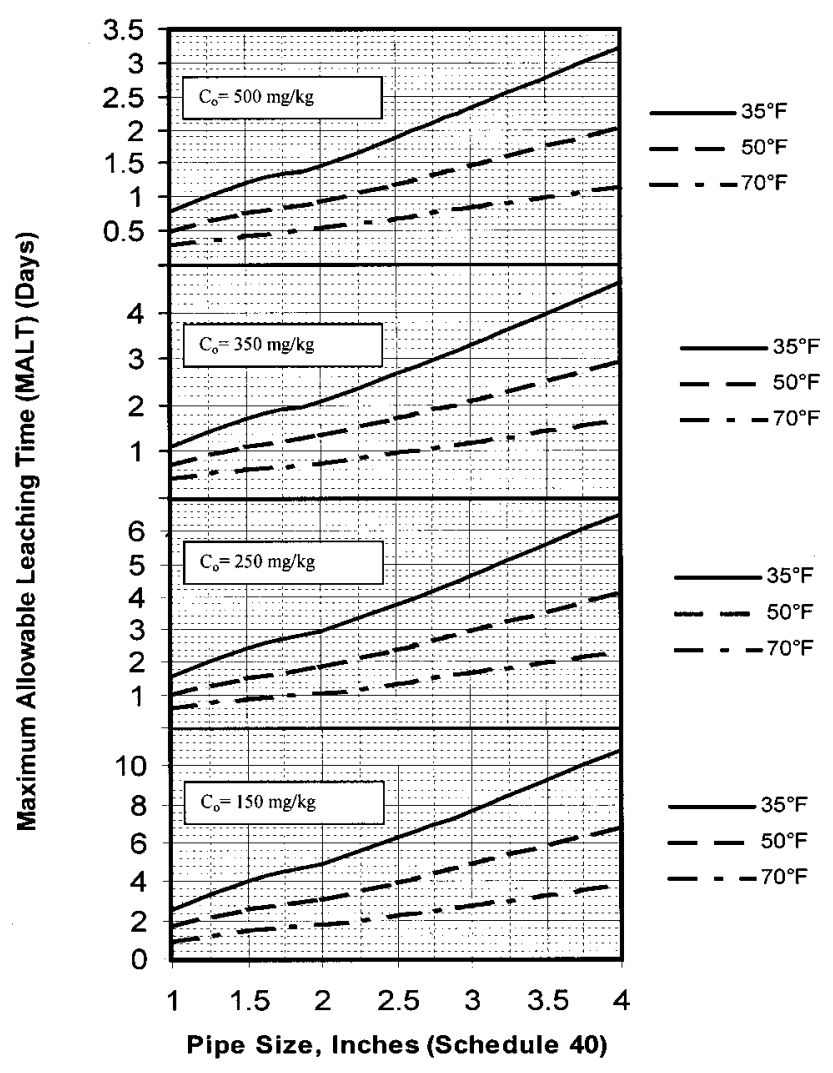

Fig. 4. Chart for calculating the maximum allowable leaching time to reach a maximum allowable concentration of $1 \mu \mathrm{g} / \mathrm{L}$ for 25 -yearold Schedule 40 PVC pipe 
Step 1-Determination of Initial Vinyl Chloride Concentrations

The utility manager has several choices as to how to determine $C_{0}$ :

1. Assume a conservative value of $500 \mathrm{ppm}$;

2. Assume a lower $C_{0}$ but be ready to monitor the resulting vinyl chloride concentrations closely to ensure that a conservative enough value was selected;

3. Have a rebound study conducted per the procedure described above to determine the actual $C_{0}$ for the specific section of pipe.

In our example, the engineer selects the conservative value of 500 ppm of vinyl chloride.

\section{Step 2-Determination of Maximum Allowable Leaching} Time

Several pieces of information are required to determine the MALT, that is, the estimated time required for the vinyl chloride concentration in the water to exceed a MAC. The following information is needed:

1. MAC (e.g., $1 \mathrm{ppb})$,

2. Water temperature, and

3. Pipe diameter.

For our example, a MAC of $1 \mathrm{ppb}$, a water temperature of $50^{\circ} \mathrm{F}$, and a pipe diameter of 2.0 in. were determined or assumed. With this information, using Fig. 4 the engineer can determine the MALT. Specifically, in this example, if $C_{0}$ is $500 \mathrm{mg} \cdot \mathrm{kg}^{-1}$, the MALT is 0.9 days.

\section{Step 3-Determination of Flush Volume}

Next, the engineer determines the required flush volume, that is, the entire dead-end pipe volume using the equation

Pipe volume (gal.)

$$
\begin{aligned}
& =(\text { pipe length, } \mathrm{ft}) \cdot\left[\frac{(\text { pipe diameter,in. })^{2} \cdot 3.14}{4}\right] \\
& \cdot 7.48 \frac{\text { gal. }}{\mathrm{ft}^{3}} \cdot \frac{1 \mathrm{ft}^{2}}{144 \mathrm{in.}^{2}} \\
& =0.04078 \cdot(\text { pipe length }, \mathrm{ft}) \cdot(\text { pipe diameter, in. })^{2}
\end{aligned}
$$

Thus, in our example, the flush volume if flushing is necessary is 645 gal.

\section{Step 4-Determination of Whether Flushing Is Required}

The criterion used to determine whether flushing is required is as follows: if less than the entire dead-end pipe volume has been used within the critical leaching time determined above, then flushing is required. Stated simply, if less than the entire dead-end volume has been used during the critical leaching period, the last plug of water may have exceeded the predetermined maximum allowable vinyl chloride concentration, and hence the entire deadend pipe must be flushed.

In many cases, it may be more convenient to think in terms of average flow rates rather than absolute volumes and times. First, we define the critical average flow rate $(\mathrm{CAF})$ as

$$
\mathrm{CAF}=\frac{\text { dead-end volume }}{\text { MALT }}
$$

In this context, the criterion for flushing is alternatively stated as follows: if the average use rate in the dead-end line (over any period of time equal to the predetermined MALT) is less than the critical average flow rate, then the line should be flushed.

\section{Step 5-Implementation of Flushing Plan and Monitoring of Results}

The purpose of the protocol just described is to serve as a guide for estimating the frequency and volume of flushes required to prevent vinyl chloride concentrations from exceeding allowable levels. Due to the uncertainty associated with the leaching model and the critical need to maintain vinyl chloride concentrations within regulatory limits, it is important that utility managers monitor the resulting vinyl chloride concentrations during the time after flushing to make certain a conservative enough value of $C_{0}$ was assumed.

The Missouri Department of Natural Resources often assumes an average use rate of 200 gallons per day per dwelling (gpd) (or 6,000 gallons per month per dwelling) (Jerry Lane, personal communication, 2000). To facilitate determination of whether flushing is likely to be needed in specific dead-end lines based, an estimated or measured average use rate can be compared with CAFs determined using Figs. 5 and 6 which correspond to dead-end lines of 1,000 and 5,500 ft, respectively.

In our example, the length of the pipe is $0.75 \mathrm{mi}$. or $3,960 \mathrm{ft}$. From Figs. 5 and 6 (for $500 \mathrm{mg} \cdot \mathrm{kg}^{-1} C_{0}, 50^{\circ} \mathrm{F}$ temperature, 2-in. pipe), we can see that the CAF is 170 and 1,000 gpd for dead-end lines of 1,000 and 5,500 ft, respectively. Interpolating to 3,960 ft, the CAF is thus $716 \mathrm{gpd}$. Since there is a single dwelling on the line, a $200 \mathrm{gpd}$ average use rate may be assumed, and the line may need to be flushed once every MALT (e.g., 0.9 days) based on the assumptions made.

\section{Effect of $C_{0}$ Assumption on Predicted Vinyl Chloride Concentrations}

The value of $C_{0}$ used in the leaching model has a significant effect on the vinyl chloride concentrations predicted for the water within the pipe. For example, very poor correlation is observed between predicted and measured vinyl chloride concentrations in the rebound studies if initial vinyl chloride concentration $\left(C_{0}\right)$ values of 100 and $500 \mathrm{mg} \cdot \mathrm{kg}^{-1}$ are assumed $(r=0.44$ and 0.29 , respectively). Thus, accurate prediction of vinyl chloride concentrations within a specific dead-end line requires calibration of the model via determination of the appropriate $C_{0}$ in a rebound study.

\section{Effect of Pipe Diameter on Predicted Maximum Allowable Leaching Time}

Pipe diameter is a significant factor with respect to the rate at which the vinyl chloride concentration increases within a deadend line. To examine this phenomenon, one must consider its two main components. First, the net vinyl chloride leaching flux $\left(\mathrm{mg} \cdot \mathrm{min}^{-1} \cdot \mathrm{m}^{-2}\right)$ is a function of PVC surface area. Second, the mass of vinyl chloride is diluted into the volume of water within a pipe, with greater volume providing greater dilution. Thus, the net effect of pipe diameter can be seen in the ratio of pipe surface area to pipe volume

$$
\frac{\text { surface area }}{\text { volume }}=\frac{\pi d L}{\pi\left(d^{2} / 4\right) L}=\frac{4}{d}
$$

In other words, the surface area to volume ratio is inversely pro- 


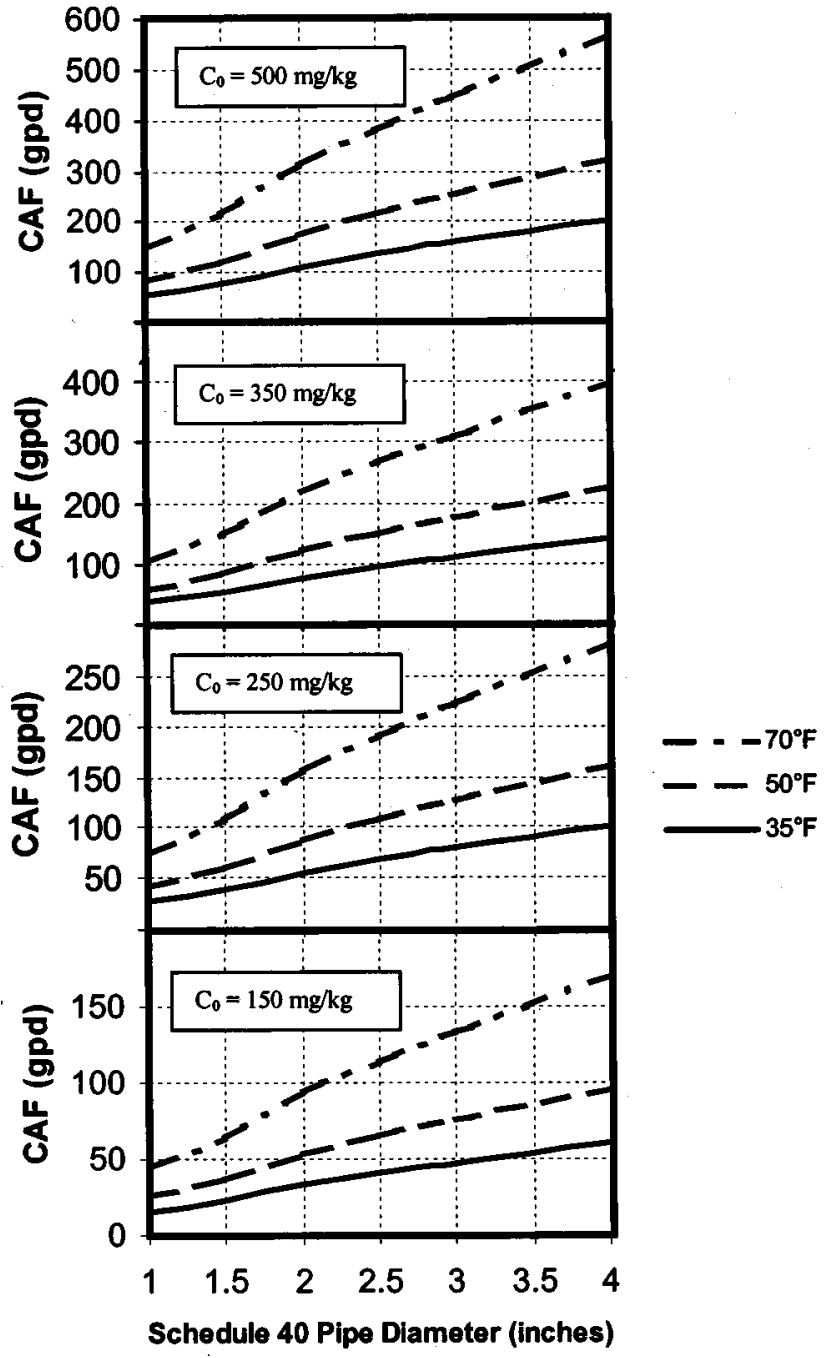

Fig. 5. Chart for calculating the critical average flow rate in a 1,000-ft dead-end line to maintain the vinyl chloride concentration below $1 \mu \mathrm{g} / \mathrm{L}$ for 25 -year-old Schedule 40 PVC pipe

portional to diameter. Therefore, smaller pipe diameters result in greater surface area to volume ratios, and hence higher vinyl chloride concentrations in solution.

To illustrate this point by example, consider the predicted MALT for a 2-in. Schedule $40 \mathrm{PVC}$ pipe at a temperature of $50^{\circ} \mathrm{F}$ with a $C_{0}$ of $350 \mathrm{mg} \cdot \mathrm{kg}^{-1}$. With an assumed MAC of $1 \mu \mathrm{g} \cdot \mathrm{L}^{-1}$, the MALT decreases from 2.9 to 0.7 days as the pipe diameter decreases from 4 to 1 in.

\section{Effect of Temperature on Predicted Maximum Allowable Leaching Time}

Several factors may affect the temperature of a dead-end pipe segment. External ground temperatures can vary with air temperature, especially in the case of pipe buried near the surface. Additionally, water temperatures may play a dominant role in determining the temperature of the pipe itself, especially if the ground surrounding the pipe moves toward the temperature of the water.

Temperature plays an important role on the rate of vinyl chloride diffusion within PVC pipe and therefore strongly affects the leaching rate of vinyl chloride into water within the pipe. Specifically, the diffusivity $(D)$ of vinyl chloride in PVC increases by $90 \%$ between 35 and $75^{\circ} \mathrm{F}$ based on Eq. (4).

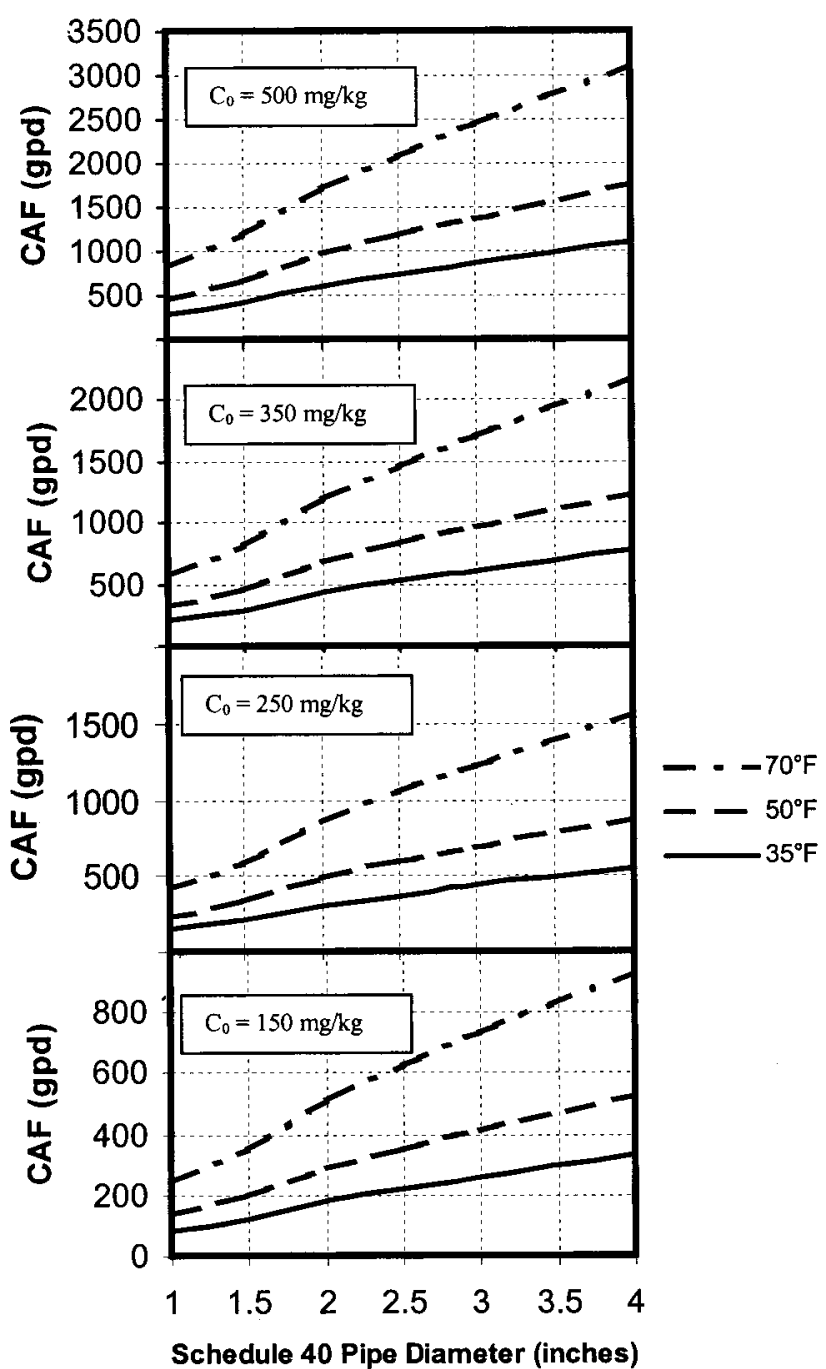

Fig. 6. Chart for calculating the critical average flow rate in a 5,500-ft dead-end line to maintain the vinyl chloride concentration below $1 \mu \mathrm{g} / \mathrm{L}$ for 25 -year-old Schedule 40 PVC pipe

To illustrate this point by example, consider the predicted MALT for a 2-in. Schedule $40 \mathrm{PVC}$ pipe at a temperature of $50^{\circ} \mathrm{F}$ with a $C_{0}$ of $350 \mathrm{mg} \cdot \mathrm{kg}^{-1}$. A temperature increase from 35 to $75^{\circ} \mathrm{F}$ results in a decrease in the MALT from 2.1 to only 0.6 days.

Because temperature changes affect the MALT so significantly, an important application of the flushing protocol developed in this research is to allow utility managers to examine the effect of temperature on their existing systems. Once a specific dead-end line is calibrated for one temperature (such as $70^{\circ} \mathrm{F}$ during the summer), the $C_{0}$ for that segment is known. Therefore the manager may predict for that segment the MALT and CAF at other temperatures, thus allowing for seasonal changes that may drop the water temperature by $30^{\circ} \mathrm{F}$ or more. The utility manager may thus predict required flush schedule changes and plan accordingly.

\section{Effect of Pipe Age on Predicted Maximum Allowable Leaching Time}

The more time that has passed since the manufacture of a pipe, the greater the degree of vinyl chloride leaching that may have taken place. Thus pipe of a lesser age may result in greater leaching into the drinking water, due to higher vinyl chloride concen- 
trations still within the PVC pipe. To illustrate this point, consider the predicted MALT for a 2-in. Schedule 40 PVC pipe at a temperature of $50^{\circ} \mathrm{F}$ with a $C_{0}$ of $350 \mathrm{mg} \cdot \mathrm{kg}^{-1}$ and MAC of 1 $\mu \mathrm{g} \cdot \mathrm{L}^{-1}$. For pipe 25 and 40 years of age, the corresponding predicted MALTs are 1.3 and 1.7 days, respectively, or a $30 \%$ increase. Therefore, the most conservative approach would to be to assume the newer age, that is 25 years, in most cases.

\section{Summary and Conclusions}

Which water distribution systems should be concerned with vinyl chloride concentrations within their water? The most conservative answer is all systems, but, more practically, only systems consisting of early-era PVC pipe are likely to observe significant vinyl chloride concentrations unless there is an alternative vinyl chloride source other than the PVC pipe.

Some of the systems examined in this study did not exhibit any rebound of vinyl chloride, presumably due to low initial vinyl chloride concentrations during their manufacture. For early-era pipes subject to vinyl chloride leaching, however, the leaching model developed in this research provides a means for utility managers to examine which dead-end lines may not require flushing due to the existing water use by connections on the line, to examine the effects of system parameters such as temperature and average use rate in dead-end pipes on resulting vinyl chloride concentrations, and to develop flush protocols.

\section{Acknowledgments}

The writers acknowledge the Missouri Department of Natural Resources (MDNR) for sponsoring this project. Additionally, we would like to thank Mr. Jerry Lane and Mr. Terry Timmons of MDNR for their help in developing and executing this work. Special thanks go to Mr. George Gering [Phelps County Public Water District (PWD) No. 2] for devoting his time and expertise to assisting the writers in this study. Finally, the writers thank all of the utility managers and operators who committed their time and effort to assist in conducting the field-site rebound studies. The information and conclusions reported here are those of the writers and do not necessarily represent those of MDNR or Phelps County PWD No. 2.

\section{References}

American Water Works Association (AWWA). (1988). "NSF recalls PVC pipe made by Pioneer International." J. Am. Water Works Assoc., 80(11), 84.

ASTM. (2000). "Standard specification for poly(vinyl chloride) (PVC) plastic pipe, Schedules 40, 80, and 120." D1785-99, West Conshohocken, Pa., 1-11.

Berens, A. (1974). "The diffusion of vinyl chloride in poly(vinyl chloride)." Polym. Prepr. (Am. Chem. Soc. Div. Polym. Chem.), 15(2), 203-208.

Berens, A., and Daniels, C. (1976). "Prediction of vinyl chloride monomer migration from rigid PVC pipe." Polym. Eng. Sci., 16(8), 552558.

Crank, J. (1956). The mathematics of diffusion, Oxford University Press, London.

Davis, R., and Frearson, M. (1987). Analytical chemistry by open learning: Mass spectrometry, Wiley, New York.

Environmental Protection Agency (EPA). (1999). Methods and guidance for analysis of water, EPA 821-C-99-004, Washington, D.C. (CD-Rom).

Letterman, R. (1999). Water quality and treatment, 5th Ed., McGrawHill, New York, 2.43-2.46.

Logan, B. (1999). Environmental transport processes, Wiley, New York.

Mansur, M. (1999). "Plastic pipe taints other water sources Texas, Arkansas confirm presence of vinyl chloride." Kansas City Star, 21 March, A4.

Merck Index. (2001). Merck and Co., Whitehouse Station, N.J.

National Sanitation Foundation (NSF). (1979). "Standard no. 14 for plastic piping system components and related materials." NSF Standards, Ann Arbor, Mich., 11-19.

O'Mara, M., and DeCapita, E. (1975), Internal Rep., B.F. Goodrich Chemical Co. (6/4/75) (cited by Berens and Daniels 1976). 